\title{
Hasil diagnostik Mycobacterium tuberculosis dari sputum penderita batuk $\geq 2$ minggu dengan pewarnaan Ziehl-Neelsen di Puskesmas Minanga Malalayang Dua, Puskesmas Bahu, dan Puskesmas Teling Atas Manado
}

\author{
${ }^{1}$ Raden M. S. Ramadhan \\ ${ }^{2}$ John Porotu'o \\ ${ }^{2}$ Olivia A. Waworuntu
}

\author{
${ }^{1}$ Kandidat Skripsi Fakultas Kedokteran Universitas Sam Ratulangi Manado \\ ${ }^{2}$ Bagian Mikrobiologi Fakultas Kedokteran Universitas Sam Ratulangi Manado \\ Email: raden.rama129@gmail.com
}

\begin{abstract}
Tuberculosis (TB) is an infectious disease which still commonly found at puskesmas (primary health care) in Manado. WHO has proclaimed "The End TB Strategy" program to reduce the incidence of TB. The TB germ can be identified with the Ziehl-Neelsen staining. This study was aimed to identify Mycobacterium tuberculosis in the sputum of patients that were suffered from cough for $\geq 2$ weeks and had not received specific therapy and of relapsed pulmonary TB patients at Puskesmas Minanga Malalayang Dua, Puskesmas Bahu, and Puskesmas Teling Atas Manado by using Ziehl-Neelsen staining. This was a descriptive prospective study with a cross-sectional design. The results showed that of 30 samples of patients, the highest percentages were as follows: at Puskesmas Teling Atas, males (60\%), ages 35-59 years old (60\%), M. tuberculosis (-) (90\%); at Puskesmas Bahu, females (60\%), ages 15-34 years old (60\%), M. tuberculosis (-) (100\%); at Puskesmas Minanga Malalayang Dua, males (60\%), ages 15-34 years old (70\%), M. tuberculosis (-) (100\%). Conclusion: Most patients had sputum with negative results of Mycobaterium tuberculosis which met the The End TB Strategy of WHO.
\end{abstract}

Keywords: Mycobaterium tuberculosis, Ziehl-Neelsen staining, tuberculosis

\begin{abstract}
Abstrak: Tuberkulosis (TB) adalah penyakit menular yang masih sering ditemukan di puskesmas Kota Manado. WHO telah mencanangkan "The End TB Strategy" program to reduce the incidence of TB. Kuman TB dapat diidentifikasi dengan pemeriksaan ZiehlNeelsen. Penelitian ini bertujuan untuk mengidentifikasi Mycobacterium tuberculosis pada sputum penderita batuk $\geq 2$ minggu yang belum mendapatkan terapi spesifik atau penderita TB paru relaps di Puskesmas Teling Atas, Puskemas Bahu, dan Puskesmas Minanga Malalayang Dua Manado dengan pewarnaan Ziehl-Neelsen. Jenis penelitian ialah deskriptif prospektif dengan desain potong-lintang. Pada hasil penilitian didapatkan 30 sampel penderita batuk $\geq 2$ minggu yang belum mendapatkan terapi spesifik atau penderita TB Paru relaps. Distribusi persentase tertinggi di Puskesmas Teling Atas ialah: laki-laki (60\%), usia 35-59 tahun (60\%), dan basil tahan asam/BTA (-) (90\%). Persentase tertinggi di Puskemas Bahu ialah: perempuan (60\%), usia 15-34 tahun (60\%), dan BTA (-) (100\%) sedangkan di Puskesmas Minanga Malalayang Dua ialah: laki-laki (60\%), usia 15-34 tahun (70\%), dan BTA(-) (100\%). Simpulan: Pada ketiga puskemas tersebut, hampir seluruh pasien mempunyai sputum BTA (-) yang memenuhi The End TB Strategy dari WHO.
\end{abstract}

Kata kunci: Mycobaterium tuberculosis, pewarnaan Ziehl-Neelsen, tuberkulosis

Tuberkulosis (TB) adalah penyakit menular yang menyerang berbagai organ manusia terutama paru-paru yang disebabkan oleh bakteri basil tahan asam yang berbentuk 
batang Gram positif (BTA +) yaitu Mycobacterium tuberculosis. ${ }^{1}$ Bakteri tersebut dapat diidentifikasi dengan pewarnaan Ziehl-Neelsen, terlihat kuman berwarna merah berbentuk batang dan latar belakang bewarna biru. ${ }^{2}$

Pada tahun 2013 di Indonesia ditemukan jumlah penderita baru BTA(+) sebanyak 196.310 orang, angka kejadian ini menurun dibandingkan dengan penderita baru BTA (+) pada tahun 2012 yang sebanyak 202.301 orang. Jumlah penderita BTA (+) tertinggi yang dilaporkan terdapat di provinsi-provinsi dengan jumlah penduduk yang besar yaitu Jawa Barat, Jawa Timur, dan Jawa Tengah. Penderita baru BTA (+) di tiga provinsi tersebut hampir sebesar $40 \%$ dari jumlah seluruh penderita baru di Indonesia. ${ }^{3}$

Pada tahun 2014 TB paru merupakan salah satu penyakit menular yang menonjol di Puskesmas Teling Atas, Puskemas Bahu, dan Puskesmas Minanga Malalayang Dua. Ditemukan jumlah kasus BTA(+) di Puskesmas Teling Atas pada wilayah cakupannya berjumlah 59 penderita dengan jumlah penderita laki-laki sebanyak 33 orang dan perempuan sebanyak 26 orang; jumlah ini mengalami penurunan dibandingkan dengan tahun 2013 yang berjumlah 66 kasus. ${ }^{4}$ Di Puskemas Bahu ditemukan jumlah penderita BTA (+) sebanyak 23 orang pada wilayah cakupannya dengan jumlah penderita lakilaki sebanyak 15 orang dan perempuan sebanyak delapan orang. 5 Di Puskesmas
Minanga Malalayang Dua ditemukan 72 penderita BTA (+) pada wilayah cakupannya dengan jumlah penderita lakilaki sebanyak 46 orang dan penderita perempuan sebanyak 26 orang. ${ }^{6}$

World Health Organization (WHO) membuat suatu program "The END TB Strategy" dengan harapan bahwa dunia bisa terbebas dari penyakit tuberkulosis. Target dari program ini salah satunya adalah mengurangi angka kejadian penyakit tuberkulosis hingga 90\% atau <10/100.000 orang pada tahun 2035 dengan perbandingan angka kejadian tuberkulosis yang terjadi pada tahun 2015 . $^{7}$

Penelitian ini bertujuan untuk mengidentifikasi Mycobacterium tuberculosis dari sputum penderita batuk $\geq 2$ minggu di Puskesmas Minanga Malalayang Dua, Puskemas Bahu, dan Puskesmas Teling Atas, Manado.

\section{METODE PENELITIAN}

Jenis penelitian ini ialah deskriptif prospektif dengan desain potong-lintang. Penelitian ini dilaksanakan pada bulan September-Desember 2015 di Laboratorium Mikrobiologi Fakultas Kedokteran Universitas Sam Ratulangi (Unsrat) Manado. Sampel sputum diambil dari penderita batuk $\geq 2$ minggu di Puskesmas Teling Atas, Puskemas Bahu, dan Puskesmas Minanga Malalayang Dua, Manado dan diperiksa dengan pewarnaan Ziehl-Neelsen.

Tabel 1. International Union against Tuberculosis and Lung Disease (IUATLD): Departemen Kesehatan RI, Pedoman Nasional Penanggulangan Tuberkulosis 2000. ${ }^{2}$

\begin{tabular}{|l|c|c|}
\hline \multicolumn{1}{|c|}{ Apa yang terlihat } & Hasil & $\begin{array}{c}\text { Apa yang } \\
\text { dituliskan }\end{array}$ \\
\hline Tidak ditemukan BTA dalam 100 lapang pandang & Negatif & Negatif \\
\hline $\begin{array}{l}\text { Ditemukan 1-9 BTA dalam 100 lapang pandang (tuliskan jumlah } \\
\text { BTA yang ditemukan) }\end{array}$ & Scanty & $\begin{array}{c}\text { Tulis jumlah } \\
\text { BTA }\end{array}$ \\
\hline Ditemukan 10-99 BTA dalam 100 lapang pandang & $1+$ & $1+$ \\
\hline $\begin{array}{l}\text { Ditemukan 1-9 BTA dalam 1 lapang pandang (periksa minimal } \\
\text { 50 lapang pandang) }\end{array}$ & $2+$ & $2+$ \\
\hline $\begin{array}{l}\text { Ditemukan } \geq 10 \text { BTA dalam 1 lapang pandang (periksa minimal } \\
\text { 20 lapang pandang) }\end{array}$ & $3+$ & $3+$ \\
\hline
\end{tabular}


Jumlah sampel yang diperoleh sebanyak 30 sampel penderita dengan jumlah sampel penderita di setiap Puskesmas sebanyak 10 orang. Terdapat tiga variabel yang diteliti yaitu: jenis kelamin (laki-laki, perempuan), kelompok usia (15-34 tahun, 35-59 tahun, $\geq 60$ tahun) dan hasil pemeriksaan BTA pada sampel sputum dengan pewarnaan Ziehl-Neelsen (BTA $(+) /(-))$.

Analisis data dan penyajian data hasil penelitian menggunakan tabel distribusi frekuensi. Hasil penilaian diagnostik menggunakan penilaian International Union against Tuberculosis and Lung Disease (IUATLD) (Tabel 1).

\section{HASIL PENELITIAN}

Pada penelitian yang dilakukan di Puskemas Teling Atas, Puskesmas Bahu dan Puskesmas Minanga Malalayang Dua, Manado, Sulawesi Utara pada periode September- Desember 2015 didapatkan 30 sampel penderita batuk $\geq 2$ minggu.

\section{Gambaran umum subjek penelitian di Puskesmas Teling Atas}

Karateristik umum subjek penelitian yang tertera dibawah ini mencakup jenis kelamin dan usia pada penderita dengan batuk $\geq 2$ minggu di Puskemas Teling Atas pada periode September - Desember 2015. Penderita berjenis kelamin laki-laki $(60 \%)$ lebih banyak dibandingkan perempuan (40\%) (Tabel 2) dan kelompok usia terbanyak ialah 35-59 tahun (60\%) (Tabel 3).

Tabel 2. Distribusi frekuensi berdasarkan jenis kelamin penderita di Puskesmas Teling Atas

\begin{tabular}{ccc}
\hline Jenis kelamin & $\mathbf{N}$ & \% \\
\hline Laki-laki & 6 & 60 \\
Perempuan & 4 & 40 \\
Jumlah & 10 & 100 \\
\hline
\end{tabular}

Tabel 3. Distribusi frekuensi berdasarkan usia penderita di Puskesmas Teling Atas

\begin{tabular}{lcc}
\hline \multicolumn{1}{c}{ Usia } & $\mathbf{N}$ & $\%$ \\
\hline 15-34 tahun & 3 & 30 \\
35-59 tahun & 6 & 60 \\
$\geq 60$ tahun & 1 & 10 \\
Jumlah & 10 & 100 \\
\hline
\end{tabular}

Gambaran hasil pewarnaan ZiehlNelseen di Puskesmas Teling Atas

Berdasarkan Tabel 4 menunjukkan bahwa penderita yang memiliki hasil Pewarnaan Ziehl-Neelsen BTA (+)dengan metode pengambilan sputum sewaktu-pagisewaktu (SPS) sebanyak 1 orang (10\%), sedangkan penderita BTA(-) dengan metode pengambilan sputum SPS sebanyak 9 orang $(90 \%)$.

Tabel 4. Distribusi frekuensi berdasarkan hasil pewarnaan Ziehl-Neelsen di Puskesmas Teling Atas

\begin{tabular}{lcc}
\hline $\begin{array}{l}\text { Hasil pewarnaan } \\
\text { Ziehl-Neelsen }\end{array}$ & N & \% \\
\hline BTA (+) & 1 & 10 \\
BTA (-) & 9 & 90 \\
Jumlah & 10 & 100 \\
\hline
\end{tabular}

Gambaran umum subjek penelitian di Puskesmas Bahu

Karateristik umum subjek penelitian yang tertera di bawah ini mencakup jenis kelamin dan usia pada penderita dengan batuk $\geq 2$ minggu di Puskemas Bahu pada periode September-Desember 2015. Penderita berjenis kelamin laki-laki (40\%) lebih sedikit dibandingkan perempuan (60\%) (Tabel 5) dengan kelompok usia terbanyak 15-34 tahun (Tabel 6).

Tabel 5. Distribusi frekuensi berdasarkan jenis kelamin penderita di Puskesmas Bahu

\begin{tabular}{lcc}
\hline Jenis kelamin & N & \% \\
\hline Laki-laki & 4 & 40 \\
Perempuan & 6 & 60 \\
Jumlah & 10 & 100 \\
\hline
\end{tabular}

Tabel 6. Distribusi frekuensi berdasarkan usia penderita di Puskesmas Bahu

\begin{tabular}{lcc}
\hline Usia & $\mathbf{N}$ & $\mathbf{\%}$ \\
\hline $15-34$ tahun & 6 & 60 \\
35-59 tahun & 2 & 20 \\
$\geq 60$ tahun & 2 & 20 \\
Jumlah & 10 & 100 \\
\hline
\end{tabular}

\section{Gambaran hasil pewarnaan Ziehl-} Nelseen di Puskesmas Bahu

Tabel 7 menunjukkan bahwa tidak terdapat penderita yang memiliki hasil 
pewarnaan Ziehl-Neelsen $\mathrm{BTA}(+) \quad(0 \%)$ dengan metode pengambilan sputum sewaktu-pagi-sewaktu (SPS).

Tabel 7. Distribusi frekuensi berdasarkan hasil pewarnaan Ziehl-Neelsen di Puskesmas Bahu

\begin{tabular}{ccc}
\hline $\begin{array}{c}\text { Hasil pewarnaan } \\
\text { Ziehl-Neelsen }\end{array}$ & $\mathbf{N}$ & $\mathbf{\%}$ \\
\hline BTA (+) & 0 & 0 \\
BTA (-) & 10 & 100 \\
Jumlah & 10 & 100 \\
\hline
\end{tabular}

Gambaran umum subjek penelitian di Puskesmas Minanga Malalayng Dua

Karateristik umum subjek penelitian mencakup jenis kelamin dan usia pada penderita dengan batuk $\geq 2$ minggu di Puskemas Minanga Malalayang Dua pada periode September-Desember 2015. Penderita yang berjenis kelamin laki-laki lebih sedikit $(60 \%)$ dibandingkan dengan perempuan (40\%) (Tabel 8) dan yang terbanyak ialah kelompok usia 15-34 tahun sebanyak 7 orang $(70 \%)$.

Tabel 8. Distribusi frekuensi berdasarkan jenis kelamin Penderita di Puskesmas Minanga Malalayang Dua

\begin{tabular}{ccc}
\hline Jenis kelamin & N & \% \\
\hline Laki-laki & 6 & 60 \\
Perempuan & 4 & 40 \\
Jumlah & 10 & 100 \\
\hline
\end{tabular}

Tabel 9. Distribusi frekuensi berdasarkan usia penderita di Puskesmas Minanga Malalayang Dua

\begin{tabular}{ccc}
\hline Usia & $\mathbf{N}$ & $\mathbf{\%}$ \\
\hline $15-34$ tahun & 7 & 70 \\
$35-59$ tahun & 0 & 0 \\
$\geq 60$ tahun & 3 & 30 \\
Jumlah & 10 & 100 \\
\hline
\end{tabular}

Gambaran hasil pewarnaan ZiehlNelseen di Puskesmas Minanga Malalayang Dua

Tabel 10 menunjukkan bahwa tidak terdapat penderita yang memiliki hasil Pewarnaan Ziehl-Neelsen BTA(+) (0\%) dengan metode pengambilan sputum sewaktu-pagi-sewaktu (SPS).
Tabel 10. Distribusi frekuensi berdasarkan hasil pewarnaan Ziehl-Neelsen di Puskesmas Minanga Malalayang Dua

\begin{tabular}{ccc}
\hline $\begin{array}{c}\text { Hasil pewarnaan } \\
\text { Ziehl-Neelsen }\end{array}$ & $\mathbf{N}$ & $\%$ \\
\hline BTA (+) & 0 & 0 \\
BTA (-) & 10 & 100 \\
Jumlah & 10 & 100 \\
\hline
\end{tabular}

\section{BAHASAN}

Distribusi sampel 10 penderita batuk $\geq 2$ minggu berdasarkan jenis kelamin di Puskesmas Teling Atas yaitu laki-laki sebanyak 6 orang $(60 \%)$ dan perempuan sebanyak 4 orang (40\%). Distribusi sampel 10 penderita batuk $\geq 2$ minggu berdasarkan jenis kelamin di Puskesmas Minanga Malalayang Dua yaitu laki-laki sebanyak 6 orang $(60 \%)$ dan perempuan sebanyak 4 orang (40\%). Hasil penelitian di kedua Puskesmas ini sesuai dengan hasil penelitian Sihotang et al. $^{8}$ mengenai gambaran penderita TB paru yang berobat menggunakan DOTS di Puskesmas Bahu Malalayang I periode Januari-Desember 2012 dengan persentasi penderita laki-laki sebanyak 33 orang $(56,90 \%)$ dan perempuan sebanyak 25 orang $(43,10 \%)$.

Hasil penelitian yang dilakukan oleh Wibowo di RSUP Manado menemukan bahwa pada laki-laki didapatkan TB paru pada kasus kontak 0,36 kali pada perempuan. ${ }^{9}$ Data WHO tahun 2006 melaporkan prevalensi TB paru 2,3 kali lebih banyak pada laki-laki di Negara yang sedang berkembang karena laki-laki dewasa lebih sering melakukan aktivitas sosial. Angka kejadian TB pada laki-laki lebih tinggi diduga akibat perbedaan pajanan dan risiko infeksi. Distribusi 10 sampel penderita batuk $\geq 2$ minggu berdasarkan jenis kelamin di Puskesmas Bahu yaitu laki-laki sebanyak 4 orang $(40 \%)$ dan perempuan sebanyak 6 orang (60\%); hal ini sejalan dengan data jumlah penduduk di Puskesmas Bahu dimana jumlah penduduk perempuan lebih banyak (13.204 orang) dibandingkan dengan jumlah penduduk laki-laki (13.194 orang). ${ }^{5}$

Beberapa penelitian juga menunjukkan bahwa perempuan memiliki rasio 
progresivitas dan case fatality rate lebih tinggi daripada laki-laki. Hal ini sesuai dengan penelitian yang dilakukan di Kabupaten Cilacap pada tahun 2012 di 6 wilayah kerja Puskesmas dengan penderita TB perempuan lebih banyak dibandingkan penderita TB laki-laki. Penderita TB perempuan yang lebih tinggi persentasenya dibandingkan penderita TB laki-laki terdapat di wilayah kerja Puskesmas: Dayeuhluhur I (57\%), Kawunganten (54\%), Jeruklegi I $(56,5 \%)$, Kesugihan I (52\%), Adipala I (54\%), dan Binangun $(56 \%){ }^{10}$ Perbedaan tersebut mungkin diakibatkan oleh perbedaan perilaku dalam mencari perawatan kesehatan antara lakilaki dan perempuan sehingga lebih banyak kasus TB pada laki-laki yang dilaporkan. ${ }^{10}$

Hal ini sesuai dengan hasil penelitian Worku dan Abebe, kelompok yang paling banyak melakukan pengobatan sendiri menurut faktor sosiodemografi seperti usia, jenis kelamin, dan pendapatan, ialah kelompok usia di bawah 30 tahun $(59,5 \%)$, jenis kelamin perempuan $(61,9 \%)$ dan kelompok berpenghasilan tinggi $(40,5 \%){ }^{12}$

Distribusi 10 sampel penderita batuk $\geq 2$ minggu berdasarkan umur di Puskesmas Teling Atas yaitu terbanyak yang berusia 35-59 tahun sebanyak 6 orang (60\%). Di Puskesmas Bahu distribusi sampel penderita batuk $\geq 2$ minggu terbanyak berusia 15-34 tahun sebanyak 6 orang (60\%). Di Puskesmas Minanga Malalayang Dua distribusi sampel penderita batuk $\geq 2$ minggu terbanyak yang berusia 15-34 tahun sebanyak 7 orang (70\%).

Tuberkulosis banyak menyerang masyarakat pada usia produktif 15-59 tahun dan meningkatkan angka kematian pada masyarakat terutama di negara berkembang. Penderita TB di kawasan Asia terus bertambah, sejauh ini Asia termasuk kawasan dengan penyebaran TB tertinggi di dunia. Empat dari lima penderita TB di Asia termasuk kelompok usia produktif. Usia produktif merupakan usia dimana seseorang berada pada tahap untuk bekerja/ menghasilkan sesuatu baik untuk diri sendiri maupun orang lain. Sekitar $75 \%$ penderita TB paru ditemukan pada usia yang paling produktif secara ekonomi (15-49 tahun). Pada usia tersebut apabila seseorang menderita TB paru, maka dapat mengakibatkan individu tidak produktif lagi bahkan menjadi beban bagi keluarganya. Diperkirakan seorang penderita TB dewasa akan kehilangan rata-rata waktu kerjanya 3-4 bulan, sehingga berdampak pada kehilangan pendapatan tahunan rumah tangganya sekitar 20-30\%. Selain merugikan secara ekonomi, TB juga mengakibatkan dampak buruk lainnya yaitu stigma sosial bahkan dikucilkan dimasyarakat. $^{12}$

Distribusi 10 sampel penderita batuk $\geq 2$ minggu berdasarkan hasil pemeriksaan pewarnaan Ziehl-Neelsen dengan metode pengambilan sampel SPS di Puskesmas Teling Atas yaitu penderita dengan hasil pemeriksaan $\mathrm{BTA}(+)$ 1+ sebanyak 1 orang (10\%) dan BTA(-) sebanyak 9 orang $(90 \%)$; hasil pemeriksaan pewarnaan ZiehlNeelsen terhadap 10 sampel penderita batuk $\geq 2$ minggu di Puskesmas Bahu dan 10 sampel di Puskesmas Minanga Malalayang Dua semua hasilnya BTA(-). Hasil pewarnaan Ziehl-Neelsen di ketiga Puskesmas ini lebih rendah dibandingkan dengan hasil pewarnaan Ziehl-Neelsen pada penderita TB Paru yang berobat di Poliklinik Paru RS. DR. M. Djamil Padang oleh Nofriyanda pada tahun 2008 dengan hasil $\mathrm{BTA}(+)$ sebanyak 205 orang $(55,26 \%){ }^{8}$

Ketidaksesuaian hasil ini mungkin disebabkan perbedaan ruang lingkup penelitian, jumlah sampel penderita serta jangka waktu penelitian namun, hasil penelitian yang dilakukan di Puskesmas Teling Atas, Puskesmas Bahu, dan Puskesmas Minanga Malalayang Dua ini telah menunjukkan keberhasilan program The END TB Strategy yang dipelopori oleh WHO dengan target mengurangi hingga 90\% angka kejadian TB paru pada tahun 2035 .

\section{SIMPULAN}

Berdasarkan hasil penelitian yang dilakukan kepada 30 sampel pasien dengan batuk $\geq 2$ minggu pada periode SeptemberDesember 2015 didapatkan angka kejadian 
TB paru BTA(+) di Puskesmas Teling Atas sebanyak 1 orang (10\%) sedangkan di Puskesmas Bahu dan di Puskesmas Minanga Malalayang Dua tidak terdapat pasien dengan $\mathrm{BTA}(+)(0 \%)$. Hal ini telah memenuhi target dari program The End Strategy of Tuberculosis.

\section{SARAN}

1. Kurangnya subjek yang tersedia menjadi salah satu faktor yang mengurangi ketepatan dari penelitian ini. Disarankan bagi peneliti lanjut untuk menggunakan subjek yang lebih banyak.

2. Dalam penelitian ini tidak dilakukan kriteria inklusi dan eksklusi yang lebih spesifik terhadap pengumpulan subjek, seperti penurunan berat badan yang signifikan, demam, pekerjaan, riwayat merokok dan lain sebagainya. Diharapkan untuk peneliti lanjut agar bisa menerapkan kriteria yang lebih spesifik lagi.

\section{DAFTAR PUSTAKA}

1. Buntuan V. Gambaran basil tahan asam (BTA) positif pada penderita diagnosa klinis tuberkulosis paru di Rumah Sakit Islam Sitti Maryam Manado periode Januari 2014 s/d Juni 2014. eBM. 2014;2:593-6.

2. Utji R, Harun H. Mycobacterium tuberculosis. In: Staf Pengajar Bagian Mikrobiologi, penyunting. Mikrobiologi Kedokteran (Edisi Revisi). Jakarta: Binarupa Aksara; p. 227-33.

3. Syafri AK. Hubungan kondisi fisik rumah dengan kejadian tuberkulosis paru di wilayah kerja Puskesmas Ngemplak Boyolali [Skripsi]. Surakarta: Fakultas Ilmu Kesehatan Universitas Muhammadiyah; 2015.

4. Data Statistik Kabupaten/Kota Manado, Data Puskesmas. Profil Puskesmas Teling Atas
Tahun 2014.

5. Data Statistik Kabupaten/Kota Manado, Data Puskesmas. Profil Puskemas Bahu Tahun 2014.

6. Data Statistik Kabupaten/Kota Manado, Data Puskesmas. Profil Puskesmas Minanga Malalayang Dua Tahun 2013.

7. World Health Organization. Global strategy and targets for tuberculosis prevention, care and control after 2015. The End TB Strategy 2015. Available from: http://www.who.int/tb/post2015_TBstrate gy.pdf

8. Sihotang RA, Lampus B, Pandelaki AJ. Gambaran penderita TB paru yang berobat menggunakan DOTS di Puskesmas Bahu Malalayang I Periode Januari-Desember 2012. Jurnal Kedokteran Komunitas dan Tropik. 2013;1:68-72.

9. Putra NR. Hubungan perilaku dan kondisi sanitasi rumah dengan kejadian TB paru di Kota Solok tahun 2011 [Skripsi]. Padang: Fakultas Kedokteran Universitas Andalas; 2011.

10. Sumarna N. Faktor-faktor yang berpengaruh terhadap kejadian tuberkulosis pada wanita di Kabupaten Cilacap Provinsi Jawa Tengah. 2014. [cited 2016 Jan 23]. Available from: http://etd.repository.ugm.ac.id/ index.php?mod=download\&sub=Downlo adFile\&act=view\&typ=html\&id $=69123$ \&ftyp=potongan \&potongan=S2-2014323689-chapter1.pdf

11. Zainul M. Hubungan kebiasaan merokok dengan konversi sputum penderita TB paru di Klinik Jemadi Medan [Skripsi]. Medan: Fakultas Kedokteran Universitas Sumatera Utara; 2009.

12. Kristina SA, Prabandari YS, Sudjaswadi R. Perilaku pengobatan sendiri yang rasional pada masyarakat. Berita kedokteran Masyarakat. 2007;23:176183. 